\title{
Alcohol use and gender effects on HIV risk behaviors in cocaine-using methadone patients
}

\author{
This article was published in the following Dove Press journal: \\ Neurobehavioral HIV Medicine \\ 19 November 2009 \\ Number of times this article has been viewed
}

\author{
Carla J Rash' \\ Nancy M Petry ${ }^{2}$ \\ 'Department of Psychiatry, \\ ${ }^{2}$ Calhoun Cardiology Center, \\ University of Connecticut Health \\ Center, Farmington, CT, USA
}

Correspondence: Nancy M Petry Calhoun Cardiology Center, University of Connecticut Health Center, 263 Farmington Avenue,

Farmington, CT 06030-3944, USA

$\mathrm{Tel}+$ I 8606792593

Fax + I 860679 I312

Email npetry@uchc.edu
Abstract: Injection drug users engage in behaviors that increase the spread of human immunodeficiency virus (HIV) and other infectious diseases. Although methadone maintenance (MM) is highly effective in decreasing heroin use and the spread of HIV, polydrug use, especially the combined use of cocaine and alcohol, is common in MM patients. Alcohol use is independently associated with HIV risk behaviors, and the effects of alcohol use on risk behaviors may vary by gender. This study evaluated the effects of recent heavy alcohol use and gender with respect to HIV risk behaviors in 118 cocaine-abusing methadone patients. Both lifetime and past month injection and sexual risk behaviors were examined. Recent heavy drinkers $(n=46)$ were more likely to be male than nonheavy drinkers $(n=72)$. Recent heavy drinkers reported more risky sexual behaviors over their lifetimes than nonheavy drinkers. Gender effects were also present for lifetime risk behaviors, with females demonstrating more sexual and injection risk behaviors than men. In terms of recent injection risk behaviors, there was a significant alcohol use by gender effect. Heavy drinking females reported significantly more drug-sharing behaviors and less frequent needle cleaning than nonheavy drinking females. Recent sexual behaviors did not differ based on alcohol use status or gender. These findings may inform HIV prevention strategies in cocaine-abusing MM patients, and they suggest that cocaine-abusing women who drink heavily are a particularly high risk group who should be counseled about risky injection drug use practices.

Keywords: HIV risk behaviors scale, gender, alcohol use, methadone maintenance, opioid dependence, cocaine use

\section{Introduction}

Injection drug users and their sexual partners are at great risk of contracting and spreading human immunodeficiency virus (HIV). Drug abuse treatment, and especially methadone maintenance (MM), is highly effective in decreasing opioid use. ${ }^{1} \mathrm{MM}$ treatments have been highlighted as an effective HIV prevention and risk reduction strategy. ${ }^{2}$ However, not all patients respond well to this intervention, and many continue using opioids as well as other drugs while maintained on methadone. Up to $50 \%$ of MM patients abuse cocaine, ${ }^{3,4}$ and cocaine use in MM patients is related to increased HIV risk-taking behaviors. Compared to their noncocaine-using counterparts, MM patients who abuse cocaine are more likely to inject drugs, share needles, have high numbers of sexual partners, and pay for or receive payment for sex..$^{5-8}$ Thus, cocaine-abusing MM patients are an important population for studying HIV risk behaviors.

Cocaine and alcohol use are a highly prevalent polysubstance use combination. Estimates indicate that $52 \%-61 \%$ of cocaine abusers also have problems with alcohol,, 910 
and in MM populations, 41\%-52\% also drink excessively. ${ }^{11,12}$ As reviewed below, alcohol use is independently associated with HIV risk behaviors, and alcohol use among cocaineabusing MM patients may exacerbate HIV risk behaviors in this particularly high-risk population.

Alcohol use is related to risky sexual activities. Among cocaine-using MM patients, past month heavy alcohol use is associated with more HIV risk related to number of sexual partners, drug-injecting and needle-sharing sexual partners, and trading sex for money or drugs. ${ }^{13}$ In a large sample of injection drug users, Arasteh and colleagues ${ }^{14}$ examined drinking patterns along with risky sexual activities over the past six months. Heavy drinkers reported more sexual partners and unprotected sex with casual partners than moderate drinkers or nondrinkers. Further, injection drug users reported same-day temporal associations between alcohol use and unprotected sexual encounters, ${ }^{14,15}$ suggesting alcohol use may be involved in decisions to not use condoms. Injection drug users reporting alcohol intoxication in the past 30 days have an eightfold and sixfold increase in the likelihood of having sex with a paying partner and trading sex for drugs or money, respectively. ${ }^{16}$

Because trading sex for drugs or money occurs more often among female substance abusers, ${ }^{17}$ gender effects may be an important consideration for understanding the interaction of alcohol use and sexual risk behaviors. Rees and colleagues ${ }^{18}$ reported a significant alcohol use by gender interaction for risky sexual activities among injection drug users; males and females with low levels of alcohol consumption had similar levels of sexual risk-taking, but females with high levels of alcohol use reported more sexual risk-taking than males who drank frequently.

Evidence relating alcohol use and drug-related risk behaviors is more mixed. For example, Rees and colleagues ${ }^{18}$ noted no association between alcohol use and risky injection drug use behaviors, but Matos and colleagues ${ }^{16}$ found that those who reported drinking to intoxication in the past month injected drugs more frequently and were more likely to share injecting equipment than those without recent alcohol use to intoxication. In samples from a needle exchange program, alcohol use was associated with greater needle-sharing behaviors, both in overall risk level ${ }^{19}$ and in same-day needlesharing risk. ${ }^{20}$ These patients used injection equipment after someone else 1.5 times more often on days in which they drank compared to nondrinking days. Gender was unrelated to overall drug HIV risk-taking ${ }^{18}$ or needle-sharing risks. ${ }^{19,20}$

The purpose of this study was to further characterize the association between alcohol use and HIV risk behaviors in cocaine-abusing methadone patients. We hypothesized that heavy alcohol use would be associated with greater sex-related HIV risk-taking and possibly drug use HIV risk behaviors. Because of the impact of gender on sex-related HIV risk behaviors, our analyses also examined main and interaction effects of gender.

\section{Method}

\section{Participants}

Participants for this study were drawn from two randomized clinical treatment trials. ${ }^{21,22}$ Both trials recruited cocaineabusing methadone patients, were conducted in the same methadone clinic, and involved randomization to standard care plus frequent urine monitoring or the same standard care plus contingency management, in which patients earned the chance to win prizes for submission of drug-negative samples. Study treatment details are not provided here as these analyses concern data collected at the intake session only; full descriptions of treatment conditions and outcomes are available from the primary reports. ${ }^{21,22}$

For both trials, inclusion criteria were a) a stable methadone dose (no changes in the past three months), b) Englishspeaking, and c) ability to comprehend study procedures (eg, no severe dementia). Both studies excluded individuals with active, uncontrolled psychosis, bipolar disorder or suicidality. Participants provided informed consent, approved by the university's institutional review board. No differences between the studies were present for recent alcohol use or lifetime or recent HIV risk behaviors $(P>0.05$; data not shown). In addition, participants in the two studies did not differ by age, gender, race, marital status, employment status, years of education, past year income, methadone dose, and years of cocaine, alcohol, or opioid use (all $P>0.05$; data not shown). Because of the similarities across studies and samples, the two trials were combined for analysis to increase power to ascertain main and interactive effects of alcohol use and gender on HIV risk behaviors.

A total of 119 participants were enrolled in the studies. ${ }^{21,22}$ We categorized participants based on recent heavy alcohol use, defined as self report of at least one episode of drinking to intoxication in the 30 days prior to the intake assessment. One individual had missing alcohol use data and was excluded from the analyses, leaving a final sample size of 118 for these analyses.

Table 1 presents demographic and baseline comparisons between the drinking groups. Heavy drinking cocaine-abusing methadone patients $(n=46)$ were more likely to be male, had more years of alcohol use and years of drinking 
Table I Descriptive characteristics of cocaine-abusing methadone patients with and without recent heavy alcohol use

\begin{tabular}{|c|c|c|c|c|}
\hline Descriptive variables & $\begin{array}{l}\text { Recent heavy alcohol use } \\
(n=46)\end{array}$ & $\begin{array}{l}\text { No recent heavy alcohol use } \\
(n=72)\end{array}$ & $\begin{array}{l}\text { Test statistic } \\
\text { (d.f.) }\end{array}$ & $P$ \\
\hline \% Randomized to CM & 44 & 53 & $X^{2}(I)=0.97$ & 0.32 \\
\hline Study (\%) & & & $X^{2}(1)=0.15$ & 0.70 \\
\hline Petry and Martin (2002) & 36 & 33 & & \\
\hline Petry and colleagues (2005) & 64 & 67 & & \\
\hline Ethnicity (\%) & & & $X^{2}(2)=2.4 I$ & 0.30 \\
\hline Hispanic & 54 & 43 & & \\
\hline African American & 35 & 36 & & \\
\hline Caucasian & 11 & 21 & & \\
\hline$\%$ Female & 57 & 83 & $X^{2}(1)=10.21$ & $<0.00$ I \\
\hline$\%$ Never married & 72 & 64 & $X^{2}(I)=0.78$ & 0.38 \\
\hline \% Unemployed or disabled & 57 & 64 & $X^{2}(1)=0.64$ & 0.42 \\
\hline \% Cocaine positive at intake & 67 & 63 & $X^{2}(1)=0.29$ & 0.59 \\
\hline$\%$ Opiate positive at intake & 30 & 31 & $X^{2}(I)=0.01$ & 0.99 \\
\hline \multicolumn{5}{|l|}{ Mean \pm SD } \\
\hline Age & $38.33 \pm 6.10$ & $39.60 \pm 6.23$ & $t(116)=1.09$ & 0.28 \\
\hline Education & $10.51 \pm 1.98$ & $11.15 \pm 2.01$ & $t(116)=1.68$ & 0.10 \\
\hline Past year income & $\$ 8750 \pm \$ 10800$ & $\$ 8700 \pm \$ 7750$ & $t(I I I)=-0.03$ & 0.98 \\
\hline Methadone dose & $71.67 \pm 27.54$ & $74.14 \pm 32.74$ & $t(I \mid 5)=0.42$ & 0.67 \\
\hline \multicolumn{5}{|c|}{ Days of substance use in past month } \\
\hline Drinking (any amount) & $8.02 \pm 9.53$ & $0.38 \pm 1.09$ & $t(46)=-5.42$ & $<0.001$ \\
\hline Drinking to intoxication & $6.57 \pm 9.53$ & $0.00 \pm 0.00$ & $t(45)=-5.10$ & $<0.001$ \\
\hline Heroin & $1.91 \pm 3.52$ & $1.36 \pm 3.81$ & $t(116)=-0.79$ & 0.43 \\
\hline Cocaine & $11.17 \pm 10.52$ & $7.36 \pm 9.76$ & $t(116)=-2.01$ & 0.05 \\
\hline Marijuana & $2.46 \pm 6.35$ & $0.93 \pm 4.97$ & $t(116)=-1.46$ & 0.15 \\
\hline Benzodiazepine & $0.09 \pm 0.35$ & $0.11 \pm 0.46$ & $t(116)=0.30$ & 0.76 \\
\hline \multicolumn{5}{|l|}{ Years of substance use } \\
\hline Drinking (any amount) & $19.43 \pm 9.42$ & $9.25 \pm 10.79$ & $t(116)=-5.25$ & $<0.001$ \\
\hline Drinking to intoxication & $12.54 \pm 8.66$ & $2.84 \pm 5.02$ & $t(64)=-6.89$ & $<0.001$ \\
\hline Heroin & $14.57 \pm 8.15$ & $16.85 \pm 8.69$ & $t(116)=1.43$ & 0.16 \\
\hline Cocaine & $13.35 \pm 7.48$ & $12.83 \pm 8.23$ & $t(116)=-0.35$ & 0.73 \\
\hline \multicolumn{5}{|l|}{ Lifetime treatment attempts for } \\
\hline Alcohol & $2.04 \pm 6.10$ & $0.18 \pm 0.57$ & $t(45)=-2.07$ & 0.05 \\
\hline Cocaine & $3.07 \pm 6.91$ & $2.47 \pm 5.30$ & $t(1 \mid 6)=-0.53$ & 0.60 \\
\hline Opiates & $8.46 \pm 8.92$ & $8.17 \pm 5.62$ & $t(68)=-0.20$ & 0.84 \\
\hline
\end{tabular}

Notes: Fluctuations in $t$-test degrees of freedom reflect use of corrected statistics for variance heterogeneity. Lifetime treatment attempts include detoxification. Abbreviations: CM, contingency management; SD, standard deviation.

to intoxication, and reported more days of alcohol use in the past month compared to those without recent heavy drinking episodes $(n=72)$.

\section{Measures and procedure}

At study intake, research assistants administered lifetime and past month versions of the HIV Risk-taking Behavior
Scale (HRBS). ${ }^{23}$ The HRBS assesses 11 HIV risk-taking behaviors in two domains, drug injecting and sexual. Each item has five response categories, which were scored from $0-5$, with higher values indicating greater risk. Drug and sex subscale scores range from $0-30$ and $0-25$, respectively. The psychometric properties of this scale are well defined, ${ }^{23-25}$ and collateral agreement with sexual partners is high. ${ }^{26}$ 
The Addiction Severity Index (ASI) ${ }^{27}$ assessed demographics, substance use history, and prior treatment attempts. Research assistants collected urine samples at study intake using Ontrak Teststicks (Roche, Somersville, NJ, USA) to screen for opioids and cocaine.

\section{Statistical analyses}

We compared sample characteristics of the recent heavy alcohol use groups (recent heavy drinking versus no recent heavy drinking) using $t$-tests and $\chi^{2}$ tests of independence. The alcohol use groups differed with respect to gender, and because gender is associated with some HIV risk behaviors, ${ }^{3,17,28}$ all subsequent analyses included gender as an independent variable.

To assess the impact of recent heavy alcohol use and gender on HIV risk behaviors, we examined the HRBS sex and drug subscales using univariate analyses of variance (ANOVA) for both lifetime and past month versions of the scale. Alcohol use group and gender were independent variables in the analyses. To account for potential age-related sources of variation as older individuals have more years to participate in more risky behaviors, ANOVAs were weighted by age using the weighted least squares procedure.

Following the examination of the sex and drug subscale scores, we investigated responses to individual HRBS items for lifetime and past month behavior. For each HRBS item, we examined the sample's response distribution according to recent heavy alcohol use status within each gender using $\chi^{2}$ tests of independence. The distribution of responses was not uniform, with some categories rarely endorsed by participants, and was sparse overall due to the nesting of analyses within gender. To account for these distributional limitations, exact $P$-values were calculated.

\section{Results}

\section{Subscale-level analyses}

Table 2 presents average age-weighted HRBS drug and sex subscale scores by recent heavy alcohol use groups and gender. Both lifetime and past month risk-taking scores are presented.

\section{Lifetime behaviors}

Significant effects of gender were present for the lifetime drug behavior subscale, $F(1,108)=4.40, P=0.04$, with females $(M=13.49, S E=0.89)$ reporting more risk behaviors compared to males $(M=10.07, S E=1.37)$. Neither the main effect of heavy alcohol use group, $F(1,108)=0.78$, $P=0.38$, nor the interaction of recent heavy alcohol use group and gender, $F(1,108)=1.49, P=0.23$, were statistically significant for drug use behavior.

For the sex-related behavior subscale, main effects for recent heavy alcohol use group and gender were both significant. Participants with recent heavy drinking episodes $(M=10.51, S E=0.55)$ reported significantly higher levels of lifetime sex-related risk behaviors compared to individuals without recent heavy drinking $(M=8.68, S E=0.57)$, $F(1,108)=5.38, P=0.02$. Women $(M=10.39, S E=0.43)$ reported greater risky sexual behaviors over their lifetimes than men $(M=8.80, S E=0.67), F(1,108)=4.00, P=0.048$. The interaction of gender and recent heavy alcohol use groups was not significant, $F(1,108)=0.78, P=0.38$.

\section{Past month behaviors}

For past month drug-related risk behaviors, main effects of alcohol use group and gender were not significant, $F(1,108)=0.41, P=0.84$, and $F(1,108)=0.24, P=0.62$, respectively. However, a significant interaction effect was

Table 2 Lifetime and past month HRBS drug and sex subscale scores by alcohol use group and gender

\begin{tabular}{|c|c|c|c|c|c|c|c|}
\hline \multirow[t]{2}{*}{ HRBS subscales } & \multicolumn{2}{|l|}{ Females } & \multicolumn{2}{|l|}{ Males } & \multicolumn{3}{|l|}{$P$-values } \\
\hline & $\begin{array}{l}\text { Recent heavy } \\
\text { alcohol use } \\
(n=26)\end{array}$ & $\begin{array}{l}\text { No recent } \\
\text { heavy alcohol } \\
\text { use }(n=56)\end{array}$ & $\begin{array}{l}\text { Recent heavy } \\
\text { alcohol use } \\
(n=19)\end{array}$ & $\begin{array}{l}\text { No recent } \\
\text { heavy alcohol } \\
\text { use }(n=I 2)\end{array}$ & Alcohol & Gender & Interaction \\
\hline \multicolumn{8}{|c|}{ Lifetime behaviors } \\
\hline Drug-related & I3.77 (I.46) & $13.22(1.02)$ & $8.36(I .7 I)$ & $11.79(2.13)$ & 0.38 & 0.04 & 0.23 \\
\hline Sex-related & II.66 (0.7I) & $9.12(0.50)$ & $9.37(0.83)$ & $8.23(1.04)$ & 0.02 & 0.048 & 0.38 \\
\hline \multicolumn{8}{|c|}{ Past month behaviors } \\
\hline Drug-related & $3.29(0.69)$ & $1.00(0.45)$ & $1.22(0.79)$ & $3.82(1.02)$ & 0.84 & 0.62 & 0.002 \\
\hline Sex-related & $3.69(0.68)$ & $1.90(0.45)$ & $3.6 \mathrm{I}(0.79)$ & $3.64(1.02)$ & 0.25 & 0.28 & 0.24 \\
\hline
\end{tabular}

Notes: Values represent age-adjusted means (standard errors) unless otherwise noted. Recent heavy drinking defined as $\geq I$ episode of drinking to intoxication in the past 30 days.

Abbreviations: HIV, human immunodeficiency virus; HRBS, HIV risk-taking behavior scale. 
present, $F(1,108)=10.23, P=0.002$. As shown in Table 2, males without a recent heavy drinking episode reported more recent risky drug using behaviors than males with a recent heavy drinking episode. For females, the pattern was reversed, such that heavy drinking was associated with greater drug risk-taking behaviors, whereas females without recent heavy drinking reported fewer risky injection drug use behaviors in the prior month.

For past month sexual behaviors, neither the main effects, nor the interaction of alcohol use group and gender were significant: alcohol: $F(1,108)=1.33, P=0.25$, gender: $F(1,108)=1.19, P=0.28$, and interaction: $F(1,108)=1.42$, $P=0.24$.

\section{Item-level analyses}

Table 3 presents the percentage of participants endorsing specified risk levels for each item of the HRBS. Each item had a five-point response category, but we present percentages dichotomized by high-risk responses and low-risk responses for each item in order to condense information. The actual responses for each item are detailed in the table, along with how percentages were dichotomized for illustrative purposes. The data are presented separately for males and females with and without recent heavy alcohol use. The right-hand columns in the table present significance levels when comparing alcohol use groups within genders.

\section{Lifetime HIV risk behaviors}

Males with and without recent heavy alcohol use differed on only one lifetime risk behavior. All of the males without recent heavy drinking reported regular drug injecting behaviors in their lifetimes, while $32 \%$ of males with heavy drinking episodes indicated they never injected regularly, $X^{2}(2,31)=6.81, P=0.03$.

Females with and without recent heavy alcohol use did not differ with respect to any of the lifetime drug use risk behaviors, but one lifetime sexual risk behavior differed based on alcohol use status. Females with recent heavy alcohol use were more likely to have engaged in paid sexual activities (with or without condoms) than females without recent heavy alcohol use, $\chi^{2}(5,82)=12.08, P=0.02$. Nonsignificant trends toward higher rates of other lifetime sexual risk behaviors (condom nonuse with casual partners and anal sex) were also noted among females with heavy alcohol use.

\section{Past month HIV risk behaviors}

Males did not demonstrate any significant differences with respect to recent drug use or sexual risk behaviors based on alcohol use status. However, a number of significant differences between alcohol use groups were present for females for drug-related risk behaviors in the past month. Females with recent heavy drinking were significantly more likely than their counterparts who did not drink heavily to report using needles after someone else, $\chi^{2}(4,82)=9.21$, $P=0.03$. Females who drank heavily in the past month also reported using needles after a greater number of other people than females who had not drank heavily in the past month, $X^{2}(2,82)=8.325, P=0.01$. The female alcohol use groups also differed significantly with respect to the frequency of cleaning needles, $X^{2}(4,82)=13.38, P=0.002$, and using bleach to clean needles $X^{2}(4,82)=17.10, P=0.001$. Again, females with recent heavy alcohol use endorsed higher levels of risk behaviors in these domains than females without recent heavy alcohol use.

\section{Discussion}

The results of this study suggest that recent heavy alcohol use patterns of MM patients may be an indicator for targeted intervention of HIV risk-taking behaviors. Cocaine-abusing MM patients with recent heavy drinking reported more lifetime sexual risk-taking compared to those without recent heavy drinking. Recent heavy alcohol use was also associated with more past month drug-related risk-taking; however, this effect was limited to females. Gender effects were noted for both drug and sexual lifetime behaviors, with females reporting more risk-taking compared to males. These findings underscore the importance of gender in understanding the impact of alcohol use on HIV risk-taking in cocaineabusing MM patients. We found main effects of gender on lifetime (but not recent) sexual and drug use risk behaviors. Some other reports also note that women substance abusers engage in higher risk-taking behaviors than their male counterparts, ${ }^{3,26}$ but others do not find such associations. ${ }^{19,20}$ The reasons for these discrepant findings are unclear, but they may relate to the manner and types of risk behaviors assessed, the sample sizes included, the time period over which risk behaviors are assessed, or the population studied. A recent study by Cavazos-Rehg and colleagues ${ }^{29}$ suggests that sexual risk-taking profiles differ by gender across several samples (cocaine-dependent treatment seekers, communitymatched cocaine-dependent peers, community-matched experimental cocaine users, and community-matched neverusers of cocaine).

Our results also confirm and extend prior findings regarding the role of alcohol use in HIV risk behaviors. Several studies have linked heavy alcohol use to sexual 
Table 3 Percentage of participants endorsing specific HIV risk behaviors by recent alcohol use group and gender

\begin{tabular}{|c|c|c|c|c|c|c|}
\hline \multirow[t]{2}{*}{ HRBS items } & \multicolumn{2}{|l|}{ Female } & \multicolumn{2}{|l|}{ Male } & \multicolumn{2}{|c|}{$\begin{array}{l}\text { Alcohol effect } \\
\text { nested by gender }\end{array}$} \\
\hline & $\begin{array}{l}\text { Heavy } \\
\text { alcohol use } \\
(n=26)\end{array}$ & $\begin{array}{l}\text { No heavy } \\
\text { alcohol use } \\
(n=56)\end{array}$ & $\begin{array}{l}\text { Heavy } \\
\text { alcohol use } \\
(n=19)\end{array}$ & $\begin{array}{l}\text { No heavy } \\
\text { alcohol use } \\
(n=12)\end{array}$ & $\begin{array}{l}\text { Females } \\
P\end{array}$ & $\begin{array}{l}\text { Males } \\
P\end{array}$ \\
\hline \multicolumn{7}{|l|}{ Lifetime drug-related behaviors } \\
\hline $\begin{array}{l}\text { Injected drugs one time/week, } 2-6 \text { times/week, one } \\
\text { time/day, 2-3 times/day or }>\text { three times/day (vs never) }\end{array}$ & 88 & 91 & 68 & 100 & 0.88 & 0.03 \\
\hline $\begin{array}{l}\text { Used needles after someone else one, two, 3-5, 6-10, } \\
\text { or }>10 \text { times (vs never shared) }\end{array}$ & 77 & 58 & 32 & 42 & 0.47 & 1.00 \\
\hline $\begin{array}{l}\text { One, two, 3-5, 6-10, or }>10 \text { persons used needles } \\
\text { before you (vs } 0 \text { ) }\end{array}$ & 73 & 58 & 35 & 42 & 0.37 & 0.50 \\
\hline $\begin{array}{l}\text { Someone used needles after you I, 2, 3-5, 6-10, } \\
\text { or }>10 \text { times (vs } 0 \text { ) }\end{array}$ & 73 & 66 & 53 & 42 & 0.83 & 0.91 \\
\hline $\begin{array}{l}\text { Cleaned needles every time, often, sometimes, rarely, } \\
\text { or never (vs does not reuse) }\end{array}$ & 88 & 82 & 58 & 83 & 0.61 & 0.38 \\
\hline $\begin{array}{l}\text { Cleaned needles with bleach every time, often, } \\
\text { sometimes, rarely, or never (vs does not reuse) }\end{array}$ & 88 & 82 & 58 & 83 & 0.94 & 0.33 \\
\hline \multicolumn{7}{|l|}{ Lifetime sex-related behaviors } \\
\hline II $-30,31-50$, or $>50$ sexual partners (vs 0,1 , or $2-10$ ) & 50 & 33 & 16 & 50 & 0.44 & 0.08 \\
\hline $\begin{array}{l}\text { Condom with regular partners often, sometimes, rarely, } \\
\text { or never (vs every time or no regular partner) }\end{array}$ & 96 & 96 & 84 & 92 & 0.45 & 0.27 \\
\hline $\begin{array}{l}\text { Condom with casual partners often, sometimes, rarely, } \\
\text { or never (vs every time or no casual partners) }\end{array}$ & 42 & 35 & 32 & 25 & 0.08 & 0.19 \\
\hline $\begin{array}{l}\text { Condom for paid sex every time, often, sometimes, } \\
\text { rarely, or never (vs no paid sex) }\end{array}$ & 73 & 44 & 37 & 17 & 0.02 & 0.75 \\
\hline Had anal sex one, two, $3-5,6-10$, or $>10$ times (vs never) & 58 & 33 & 32 & 8 & 0.09 & 0.33 \\
\hline \multicolumn{7}{|l|}{ Past month drug-related behaviors } \\
\hline $\begin{array}{l}\text { Injected drugs one time/week, 2-6 times/week, one } \\
\text { time/day, 2-3 times/day or }>3 \text { times/day (vs never) }\end{array}$ & 42 & 21 & 32 & 58 & 0.12 & 0.25 \\
\hline $\begin{array}{l}\text { Used needles after someone else I, 2, 3-5, 6-10, } \\
\text { or }>10 \text { times (vs never shared) }\end{array}$ & 23 & 4 & 0 & 0 & 0.03 & - \\
\hline $\begin{array}{l}\text { One, two, 3-5, 6-10, or }>10 \text { persons used needles } \\
\text { before you (vs } 0 \text { ) }\end{array}$ & 19 & 4 & 0 & 0 & 0.01 & - \\
\hline $\begin{array}{l}\text { Someone used needles after you one, two, 3-5, 6-10, } \\
\text { or }>10 \text { times (vs } 0 \text { ) }\end{array}$ & 15 & 4 & 0 & 0 & 0.07 & - \\
\hline $\begin{array}{l}\text { Cleaned needles every time, often, sometimes, rarely, } \\
\text { or never (vs does not reuse) }\end{array}$ & 31 & 9 & 16 & 42 & 0.002 & 0.08 \\
\hline $\begin{array}{l}\text { Cleaned needles with bleach every time, often, } \\
\text { sometimes, rarely, or never (vs does not reuse) }\end{array}$ & 31 & 9 & 16 & 42 & 0.001 & 0.23 \\
\hline \multicolumn{7}{|l|}{ Past month sex-related behaviors } \\
\hline Two, $3-5,6-10$, or $>10$ sexual partners (vs 0 or I) & 15 & 4 & 16 & 0 & 0.21 & 0.15 \\
\hline $\begin{array}{l}\text { Condom with regular partners often, sometimes, rarely, } \\
\text { or never (vs every time or no regular partner) }\end{array}$ & 46 & 27 & 53 & 67 & 0.14 & 0.16 \\
\hline $\begin{array}{l}\text { Condom with casual partners often, sometimes, rarely, } \\
\text { or never (vs every time or no casual partners) }\end{array}$ & 12 & 5 & 11 & 0 & 0.40 & 1.00 \\
\hline $\begin{array}{l}\text { Condom for paid sex every time, often, sometimes, } \\
\text { rarely, or never (vs no paid sex) }\end{array}$ & 11 & 2 & 5 & 0 & 0.09 & 1.00 \\
\hline Had anal sex one, two, $3-5,6-10$, or $>10$ times (vs never) & 4 & 5 & 5 & 0 & 0.81 & 1.00 \\
\hline
\end{tabular}

Notes: Provided $P$-values correspond to the exact significance value of chi-squared tests of independence examining effects of alcohol use category within each gender using all response categories. For brevity, we provide collapsed percentages for the participants endorsing specified levels (eg, $\geq I$ time, often or less frequently) of risk behavior. Abbreviations: HIV, human immunodeficiency virus; HRBS, HIV risk-taking behavior scale. 
risk-taking behaviors. ${ }^{13,14,16}$ Similarly, participants with recent heavy drinking in our study had higher overall lifetime sexual risk behaviors than those who were not recent heavy drinkers.

The interaction between alcohol use and gender noted in this study is similar to that reported by Rees and colleagues. ${ }^{18}$ Recent heavy alcohol use in females was associated with more drug-related risk-taking compared to females without recent heavy drinking. The relation between recent heavy drinking and drug-related risk behaviors appears to function differently among males, with recent heavy drinkers reporting less drugrelated HIV risk-taking than their nonheavy drinking male counterparts. Differing alcohol use motives (eg, drinking to cope versus drinking in place of using drugs) and/or temporal drinking patterns (eg, drinking before drug-using situations) between genders may contribute to such different effects between alcohol and risk-taking. Few other studies have examined gender effects together with alcohol use patterns in understanding HIV risk behaviors (see Randolph and colleagues ${ }^{30}$ for an examination of gender, alcohol use and expectancies, and sexual risk-taking in a college sample). Our results in conjunction with those of Rees and colleagues ${ }^{18}$ suggest gender is an important factor for understanding the impact of alcohol on both sexual and drug-taking risk behaviors.

The item-level analyses suggest specific areas to target for HIV risk reduction, especially ongoing intravenous injection behaviors in heavy drinking cocaine-abusing female MM patients. Females with recent heavy alcohol use endorsed higher risk levels on items related to using needles after someone else, using needles after multiple other persons, needle cleaning, and use of bleach for cleaning needles. Our findings highlight specific subgroups of the cocaine-abusing MM population (eg, females with recent heavy alcohol use) and specific behaviors to address in HIV risk interventions. However, we note that HIV risk-taking levels were high for the entire sample, and our findings do not negate the need for HIV risk education for all cocaine-abusing MM patients.

Strengths of the current study include the use of a particularly high-risk population (ie, polydrug-abusing MM patients) and the assessment of both lifetime and recent risk behaviors. HIV risk reduction is an important and timely topic for the MM population. Our results suggest that even relatively low levels of alcohol problems ( $\geq 1$ episode of intoxication in past 30 days) can be a useful indicator for understanding and intervening in HIV risk behaviors, particularly when gender is also considered.

Study limitations include use of self-reported HIV risk behaviors and past month alcohol use patterns.
However, Darke ${ }^{31}$ suggests that both drug use self-reports and HIV risk-taking self-reports by injection drug users and MM patients are consistently reliable and valid across a number of studies when confidentiality of the participants' self-report is ensured, a practice employed in the current study. Because HIV status was not assessed in this study, we are unable to relate the impact of infection on risk behaviors.

Cocaine-abusing MM patients represent a substantial portion $(\sim 50 \%)$ of the MM patient base. Research suggests that cocaine use during MM treatment often remains unchanged, even when other drug use decreases. ${ }^{32,33}$ Given evidence that cocaine use during MM treatment negatively impacts treatment outcomes (eg, heroin use) and is associated with continuation of high risk behaviors (eg, injection, needle-sharing), ${ }^{33}$ the cocaine-using MM population warrants additional attention from clinicians. Results from this study provide additional information for clinicians to tailor targeted interventions for HIV risk reduction to specific risk areas given alcohol use status and gender.

Involvement in MM programs provides an ideal opportunity for HIV risk reduction efforts, and a substantial amount of research suggests that such harm reduction efforts are effective in reducing risk behaviors., ${ }^{2,3,13,34,35}$ Although polydrug-abusing MM patients present significant challenges to treatment efforts, data suggest HIV risk reduction is possible even among patients who continue abusing cocaine during MM treatment. ${ }^{13}$ Results of the present study provide further characterization of the effects of alcohol use and gender on HIV risk behaviors among cocaine-abusing MM patients and suggest areas of focus for HIV risk reduction efforts within this high-risk population.

\section{Disclosures}

The authors report no conflicts of interest in this work. This research was supported by NIH grants T32-AA07290, P30DA023918, R01-DA016855, R01-DA14618, R01-DA12056, R01-DA13444, R01-MH60417-Suppl., R29-DA12056, P50-DA09241, P50-AA03510, with additional funding from the General Clinical Research Center Grant M01-RR06192.

\section{References}

1. Ball JC, Ross A. The Effectiveness of Methadone Maintenance Treatment: Patients, programs, services, and outcomes. New York, NY: Springer-Verlag; 1991.

2. Sorensen JL, Copeland AL. Drug abuse treatment as an HIV prevention strategy: A review. Drug Alcohol Depend. 2000;59:17-31.

3. Camacho LM, Bartholomew NG, Joe GW, Cloud MA, Simpson DD. Gender, cocaine, and during-treatment risk reduction among injection opioid users in methadone maintenance. Drug Alcohol Depend. 1996 41:1-7. 
4. Sees KL, Delucchi KL, Masson C, et al. Methadone maintenance vs 180-day psychosocially enriched detoxification for treatment of opioid dependence. JAMA. 2000;283(10)1:303-1310.

5. Bux DA, Lamb RJ, Iguchi MY. Cocaine use and HIV risk behavior in methadone maintenance patients. Drug Alcohol Depend. 1995;37: 29-35.

6. Darke S, Baker A, Dixon J, Wodak A, Heather N. Drug use and HIV risk-taking behavior among clients in methadone maintenance treatment. Drug Alcohol Depend. 1992;29:263-268.

7. Grella CE, Anglin MD, Wugalter SE. Cocaine and crack use and HIV risk behaviors among high-risk methadone maintenance patients. Drug Alcohol Depend. 1995;37:15-21.

8. Joe GW, Simpson DD. HIV risks, gender, and cocaine use among opiate users. Drug Alcohol Depend. 1995;37:23-28.

9. Heil SH, Badger GJ, Higgins ST. Alcohol dependence among cocainedependent outpatients: Demographics, drug use, treatment outcomes, and other characteristics. J Stud Alcohol. 2001;62:14-22.

10. Rash CJ, Alessi SA, Petry NM. Cocaine abusers with and without alcohol dependence respond equally well to contingency management treatments. Exp Clin Psychopharmacol. 2008;16:275-281.

11. Hillebrand J, Marsden J, Finch E, Strang J. Excessive alcohol consumption and drinking expectations among clients in methadone maintenance. J Subst Abuse Treat. 2001;21:155-160.

12. Rittmannsberger H, Silberbauer C, Lehner R, Ruschak M. Alcohol consumption during methadone maintenance treatment. Eur Addict Res. 2000;6:2-7.

13. Magura S, Rosenblum A, Rodriguez EM. Changes in HIV risk behaviors among cocaine-using methadone patients. J Addict Dis. 1998;17(4):71-90.

14. Arasteh K, Jarlais DCD, Perlis TE. Alcohol and HIV sexual risk behaviors among injection drug users. Drug Alcohol Depend. 2008;95:54-61.

15. Stein MD, Anderson B, Charuvastra A, Friedmann PD. Alcohol use and sexual risk taking among hazardously drinking drug injectors who attend needle exchange. Alcohol Clin Exp Res. 2001;25(10):1487-1493.

16. Matos TD, Robles RR, Sahai H, et al. HIV risk behaviors and alcohol intoxication among injection drug users in Puerto Rico. Drug Alcohol Depend. 2004;76:229-234.

17. Totu S, Goldstein M, Deren S, et al. Urban crack users: Gender differences in drug use, HIV risk, and health status. Women Health. 1998;27:177-189.

18. Rees V, Saitz R, Horton NJ, Samet J. Association of alcohol consumption with HIV sex- and drug-risk behaviors among drug users. J Subst Abuse Treat. 2001;21:129-134.

19. Stein MD, Hanna L, Natarajan R, et al. Alcohol use patterns predict high-risk HIV behaviors among active injection drug users. $J$ Subst Abuse Treat. 2000;18:359-363.

20. Stein MD, Charuvastra A, Anderson B, Sobota M, Friedmann PD. Alcohol and HIV risk taking among injection drug users. Addict Behav. 2002;27:727-736.
21. Petry NM, Martin B. Low-cost contingency management for treating cocaine- and opioid-abusing methadone patients. J Consult Clin Psychol. 2002;70:398-405.

22. Petry NM, Martin B, Simcic F. Prize reinforcement contingency management for cocaine dependence: Integration with group therapy in a methadone clinic. J Consult Clin Psychol. 2005;73:354-359.

23. Ward J, Darke S, Hall W. The HIV Risk-taking Behavior Scale (HRBS) Manual (Technical Report No. 10). Sydney, Australia: National Drug and Alcohol Research Centre; 1990.

24. Kelley JL, Petry NM. HIV risk behaviors in male substance abusers with and without antisocial personality disorder. J Subst Abuse Treat. 2000;19:59-66.

25. Petry NM. Reliability of drug users' self-reported HIV risk behaviors using a brief, 11-item scale. Subst Use Misuse. 2001;36:1731-1747.

26. Darke S, Hall W, Heather N, Ward J, Wodak A. The reliability and validity of a scale to measure HIV risk-taking behavior among injection drug users. AIDS. 1991;5:181-185.

27. McLellan AT, Luborsky L, Cacciola J, et al. New data from the Addiction Severity Index: Reliability, and validity in three centers. J Nerv Ment Dis. 1985;17:412-423.

28. Darke S, Swift W, Hall W, Ross M. Predictors of injecting and injecting risk-taking behavior among methadone maintenance clients. Addiction. 1994;89:311-316.

29. Cavazos-Rehg PA, Spitznagel EL, Schootman M, et al. Risky sexual behaviors and sexually transmitted disease: A comparison study of cocaine-dependent individuals in treatment versus a communitymatched sample. AIDS Patient Care STDs. 2009;23:727-734.

30. Randolph ME, Torres H, Gore-Felton C, Lloyd B, McGarvey EL. Alcohol use and sexual risk behavior among college students: Understanding gender and ethnic differences. Am J Drug Alcohol Abuse. 2009;35:80-84.

31. Darke S. Self-report among injecting drug users: A review. Drug Alcohol Depend. 1998;51:253-263.

32. Grella CE, Anglin MD, Wugalter SE. Patterns and predictors of cocaine and crack use by clients in standard enhanced methadone maintenance treatment. Am J Drug Alcohol Abuse. 1997;23:15-43.

33. Williamson A, Darke S, Ross J, Teesson M. The effect of persistence of cocaine use no 12-month outcomes for the treatment of heroin dependence. Drug Alcohol Depend. 2006;81:293-300.

34. Camacho LM, Bartholomew NG, Joe GW, Simpson DD. Maintenance of HIV risk reduction among injection opioid users: A 12 month posttreatment follow-up. Drug Alcohol Depend. 1997;47:11-18.

35. Longshore D, Hsieh SC. Drug abuse treatment and risky sex: Evidence for a cumulative treatment effect? Am J Drug Alcohol Abuse. 1998;24(3):439-452.
Neurobehavioral HIV Medicine

\section{Publish your work in this journal}

Neurobehavioral HIV Medicine is an international, peerreviewed, open access journal focusing on advances in research in HIV/AIDS, with specific reference to the neurological, psychiatric and behavioral consequences of the disease, concomitant infections and specific antiretroviral therapy. The manuscript

\section{Dovepress}

management system is completely online and includes a very quick and fair peer-review system, which is all easy to use. Visit http://www.dovepress.com/testimonials.php to read real quotes from published authors. 